Review Article

DOI: $10.36959 / 763 / 500$

\title{
Primate Cognition and the Origins of Human Culture
}

\author{
Simon Dein* \\ Queen Mary College, University of London, UK
}

\begin{abstract}
The concept of culture is central to cross cultural psychology. This paper examines the evolutionary roots of human culture through examining the similarities and differences between human and non-human primates. After discussion of the meaning of the term culture, I present evidence that it is to be found in non-human primates with a focus upon chimpanzees. I then discuss how human culture differs from that of its non-human cousins. I consider several factors which might account for the relative sophistication of human culture: Learning, the ratchet effect, conformity, collaboration, meta-representation, and imagination.
\end{abstract}

\section{Introduction}

As Chasiotis [1] has argued, cross-cultural psychology aims to look for and account for similarities and differences in the behaviour of individuals in diverse cultural groups. It links human behaviour to its cultural context [2]. Poortinga [3] notes that research in cross-cultural psychology focuses upon differences rather than similarities in psychological functioning. Consequently, stereotyped views of 'them' versus 'us' are promoted. Furthermore Keller, Poortinga, \& Schölmerich [4] bemoan the fact that the cross cultural psychological literature pays sparse attention to evolutionary approaches. Evolutionary aspects are rarely mentioned in the cross-cultural literature despite the fact that they have direct relevance for cultural psychology.

A pressing question for anthropologists is: What differentiates humans from other primate species? To what degree do nonhumans share other capacities still thought to be exclusively human? Answers to these questions have focused on diverse areas including, but not exclusively, cognition, styles of cooperation, tool use, influence on the surrounding environment, and niche construction. While much progress has been made in defining uniquely human cognitive aspects, much less understanding exists of the evolutionary processes involved in generating these differences [5]. To this extent Heyes [6] notes that evolutionary research on human cognition asks what types of cognition make humans unique, and how they arise through evolutionary pathways.

Laboratory-based studies of primate cognition are somewhat problematic to the extent that captive populations of a species are not always comparable, and it may not be possible to generalize to natural populations. Field studies of primate cognition can pose significant difficulties in that that replications are costly and difficult to conduct, and similarly different populations cannot be easily compared. In an attempt to resolve these issues, Tomasello and Call [7] propose the creation of data banks for the deposition of primary data and videotapes so as to facilitate cross-examination, replication, and, eventually, the grouping together of data across investigative groups.

The study of nonhuman primate culture may provide significant understandings into the development of human culture, since it is likely that evolutionary continuities link human and nonhuman primate cognitive processes. Thus examination of chimpanzees, our closest living relatives, can inform us about cognition in the common primate ancestor and determine which human cognitive aspects are shared with other non-human primates and which may have evolved more recently. Evidence exists for both commonalities and major differences here and indicate a more gradual and incremental process of human evolution than previously assumed.

\section{Do Primates Have Culture?}

Whether primates have culture has been a topic of longstanding debate among biologists and biological anthropologists and rests on the definition of the term 'culture' [8]. As Sahlins [9] argues in The Uses and Abuses of Biology, social scientists have been reluctant to compare humans with animals and to use the term culture for non-human species for fear of threatening human beings in their humanity [10]. In terms of culture, many scholars assert that some animal behaviors are 'cultural' to the extent that they are socially trans-

*Corresponding author: Professor Simon Dein, Queen Mary College, University of London, UK

Accepted: May 22, 2019

Published online: May 24, 2019

Citation: Dein S (2019) Primate Cognition and the Origins of Human Culture. Insights Anthropol 3(1):179-184 
mitted inter-generationally. They fulfill the widely accepted definition of animal traditions as 'a distinctive behavior pattern shared by two or more individuals in a social unit, which persists over time and that new practitioners acquire in part through socially aided learning' [11].

Evidence is rapidly accumulating that non-human primates indeed do have culture. This evidence questions the longstanding premise among sociocultural anthropologists that it is only humans who have culture. Not only do chimpanzees as a species demonstrate a wide range of traditions, but, significantly, each community possesses its own set of cultural traditions. These cultural traits involve not only feeding patterns but also exist in the communicative and social domains. Such diversity has been found in various contexts: Sexual, social, demographic, tool-use, and hunting. Chimpanzees are skilled in tool use with different groups deploying diverse tools to resolve identical problems $[12,13]$. These behavioural differences cannot be accounted for genetically [14]. The first indication that non-human primates have culture derives from fieldwork among macaques in the 1950s in Japan [15]. A female monkey on Koshima Island was observed rinsing sweet potatoes prior to eating them. This behaviour was subsequently transmitted throughout the troop.

\section{Food Processing and Tool Use}

Information pertaining to primate culture may be elicited through examination of tool construction and use. A tool may be defined as an implement which facilitates a specific purpose. It is important to distinguish between tool use and tool making, the latter involves deliberately modifying some material for its intentional use. Tool use is generally considered to signify complex cognitive abilities and at one time was indeed considered to be unique to humans. However non-human primates and birds also deploy tools for gathering food. The sophistication of human tools and the degree of reliance upon them is unique among humans and is what differentiates this group from other species.

Primates are recognized for using tools in a range of activities like hunting and foraging for food and water, finding shelter, and self-defence. Whiten [16] argues that chimp tool use helps the community survive through seasonal nutritional bottlenecks. While chimpanzees and bonobos are our closest living relatives, they differ in their use of tools. Chimpanzees demonstrate a diverse range of tool use but bonobos, on the other hand, rarely use tools and never in these cases for foraging for food.

Chimps alter objects so as to make them fit for specific purposes. They can make objects for use in the future at some distant location, and they demonstrate some creative ability in terms of using objects as tools to solve novel problems. Such actions indicate a degree of planning and forethought and interest in the shape and size of the raw material, reflecting some preconceived ideas of what the end product should be. One significant feat among chimps is that they learn to use a tool set. Eastern and West African chimpanzees sequentially deploy four tools to extract honey. These are gathered together specifically for this purpose. They begin with a battering stick, followed by a chisel-like stick, then a hard-pointed stick, and finally they end by using a long slender flexible dip stick to extract the honey.

Tool use traditions differ in different geographical areas. As one illustrative example, two groups of chimpanzees in Uganda, the Sonso community of the Budongo Forest and the Kanyawara community of the Kibale Forest, were exposed to an identical problem involving the extraction of honey trapped inside a cavity of a large tree trunk [17]. There are negligible genetic differences between these communities and both are very similar ecologically.

The two groups demonstrated differences in their use of sticks for foraging. Group-specific techniques were deployed by each community reflecting their cultural backgrounds, i.e., stick use in Kanyawara and leaf-sponging in Sonso. Hence, the chimpanzees adapted previously acquired tool use behavior to solve a novel foraging problem. Importantly, despite the fact that all Kanyawara chimpanzees could make leaf sponges no individuals used this technique to solve this particular problem. The Kanyawara chimpanzees regularly make use of sticks to obtain food from inside cavities, but the use of sticks has not been observed in the Sonso community after repeated observations over two decades $[17,18]$. The findings demonstrate that after controlling for genetic and environmental influences, wild chimpanzees depend upon their culture specific information for solving a novel task.

As another example Preutz, et al. [19] observed Savannah chimps at Fongoli, Senegal. The authors found that these primates consistently deployed tools-pointed spears-to hunt for prey-usually bush babies. After tearing off the bark from a branch they bite it to fashion a spear which they use to jab their prey. Of great interest it was predominantly females who used tools. This research raises interesting questions related to tool use in early hominids and especially the role of females in hunting.

\section{Cognition in Human and Non-Human Primates}

As Boesch [10] notes, the central question pertaining to primate culture concerns the diverse cultural practices in different species rather than whether culture is unique to humans. The focus of research has now changed from whether primates have culture to how their culture differs from that of humans. However, some [20], have argued contra this position that only humans have a completely developed symbolic activity through evolution that integrates all the intelligence modules of the human mind. Furthermore, it is unknown whether chimpanzees have a form of internal subjectivity and to what extent they ascribe symbolic meanings to their behaviours. Finally, as Gruber, et al. [21] assert, for some authors culture comprises not only a collection of socially acquired behaviours, but also an integrated set of norms vigorously defended by individuals $[22,23]$.

While humans and other great apes share many cognitive abilities (including symbolic communication), the main differences involve complex cognitive skills in humans including reasoning about relationships, causation, time, and other minds. Whiten and Erdal [24] identify five dimensions of the human socio-cognitive niche on which humans excel 
compared to non-human primates - cooperation, egalitarianism, theory of mind, language, and culture. They cite several illustrative examples. Chimpanzees cooperate during hunting and raiding parties on other troops; are egalitarian in sharing food, form coalitions to oppose dominant males; can attribute perceptions and goals, and perhaps even beliefs and desires, to other chimpanzees; and, as well as possessing large repertoires of communicative gestures, they make use of flexible, context dependent gestures to communicate essential information about food, the environment and social roles. Whiten and Erdal note the vast differences between the cultural abilities of chimpanzees and humans, but even here signs of continuity are be found. Field studies indicate that over forty chimpanzee traditions from food processing, to tool use, to social behaviours and including many of the social learning processes observed in humans can be found in other animals like chimpanzees.

Significant differences exist in social learning processes between humans and non-human primates, however. Humans deploy shared intentionality to an extent not found in other primate groups for collaborative living, social learning, and information exchanges in groups. Furthermore, there is accumulating evidence that our lineage underwent significant physical changes, behavior, and ecological environments during the Pleistocene resulting in the development of a specifically human niche. As Fuentes [25] argues, no other species expresses such marked ecological diversity as humans. While human niches are material, they are simultaneously shaped by perceptions, beliefs, hopes, and practices, and our ideologies have impacted the evolutionary process. He underscores the fact that human culture can be distinguished from primate culture in encompassing numerous variations spans an immense diversity of behaviour, technology, ideas, and many other aspects. No other species comes remotely close to this. Fuentes [25] arguing for the distinctiveness of human culture writes:

'For humans, cultural elements include massive extrasomatic material creation, manipulation, and use (tools, weapons, clothes, buildings, towns, etc.) and extensive ratcheting up (expansion and augmentation of cultural processes based on accumulation and innovation) on scales and with a level of structural and material complexity greater than in other organisms'.

How can we explain the significant differences between human and non-human primate cultures? Below some aspects that differentiate between human and non-human primates and may account for the superior cultural abilities of human primates will be examined. These include learning; cumulative culture; conformity, meta-representation, collaboration, and imagination beginning with learning. While they are examined separately they are interrelated. For instance as shall be discussed below human learning is dependent upon meta-representational ability. The capacity for the development of cumulative culture is underpinned by the human propensity to learn.

\section{Learning in Human and Non-Human Primates}

One difference between human and animal culture in- volves social learning processes. Musgrove, et al. [26] define teaching as a form of high-fidelity social learning that facilitates the development of human cumulative culture. Arguably, only human culture derives from imitation and teaching, while animal cultures on the other hand originate from 'lower-level' social learning involving stimulus enhancement or emulation [27-31]. It is of note that human children are especially attuned to adults imparting knowledge about various aspects of their environments [32]. This adult instruction is trusted implicitly based on their cooperative motives. There is generally little supporting evidence for teaching in non-human primates. This contrasts markedly with the habitual natural teaching practices which are found universally in diverse cultural groups (but see for some evidence of the existence of teaching in non-primate species) $[33,34]$.

Csibra and Gergerly [35] argue that the types of knowledge transmitted across generations in human groups are significantly different from the more restricted range of socially transmitted cultures that are to be found in non-human primates. These authors argue that during hominid evolution a new type of specialized social learning system was selected to ensure that cognitively opaque cultural contents were efficiently transmitted inter-generationally from knowledgeable individuals to conspecifics lacking such knowledge. Human communication enables individuals to impart knowledge with opaque content to others through a single demonstration. This occurs not only because recipients are already attuned to view such actions as communicative demonstrations involving cultural knowledge which can be generalised to other pertinent dimensions . They ie Csibra and Gergerly [35]: 'First, human cultures are unique in that they involve the transmission of cognitively opaque cultural knowledge that is not (or not fully) comprehensible for the naïve observational learner in terms of their relevant causal and/or teleological properties. Second, human cultures involve the transmission of generic (or semantic) knowledge of properties that specify and generalize to kinds. Third, human cultures involve conveying shared cultural knowledge that is presumed to be equally accessible to all members of one's cultural group'.

\section{Cumulative Culture and The Ratchet Effect}

'Cumulative culture' originates from individuals' abilities to 'ratchet' existing culturally transmitted achievements, that is to "...add an existing technique used in a different context, or an entirely novel technique, to an existing technique, and integrate them functionally" [36]. As Tomasello [37] notes, human beings are biologically adapted for culture in significant ways compared to other primates. This is evidenced most clearly by the fact that only human cultural traditions accumulate modifications over historical time (referred to as the ratchet effect). Human culture is dependent upon evolutionary processes in which material and symbolic artefacts and social practices slowly acquire increasing numbers of modifications (ratchet up in complexity), upon which other group members can build [38].

However while some authors assert that human cumulative culture results from teaching and imitation $[22,29,39]$ others argue that human-animal differences in 
social learning mechanisms may be insufficient sufficient to explain the emergence of cumulative culture [40].

\section{Conformity}

In terms of conformity - aligning one's attitude with a majority position-recent studies indicate that conformity can be observed in animals who may reject pre existent individual preference for the majority's preference [4144]. However little is known about the cognitive processes underpinning these behaviours. More specifically could it be that animals are biased to accept the majority choice (informational conformity) or does this conformity derive from social awareness and the desire to conform to the group (normative conformity) $[43,45,46]$. Some suggestive evidence for informational conformity can be seen among vervet monkeys. Immigrating males who developed a strong likeness for one type of novel food (artificially colored blue or pink maize of identical taste) in their group of origin quickly altered their food preferences shortly after migrating in a group where the majority of individuals demonstrated a preference for the other colour [47]. Given that normativity requires some representation of norms and its more complex expression, the existence of informational conformity in nonhuman groups remains controversial [48].

\section{Meta-Representation and Culture}

While humans and other great apes hold many cognitive skills in common, the former also developed a unique assemblage of cognitive abilities and motivations - collectively known as shared intentionality - to facilitate collaboration, social learning, and information exchange within cultural groups. Tomasello [38] suggests that the capacity for theory of mind among humans enabled them to view their peers as intentional beings who possess similar minds. For Tomasello, et al. [49], this cultural capacity is dependent upon this enhanced social cognition, particularly this ability is closely associated with language which facilitates the formation of categories of mental states and conscious awareness of their existence [50]. Chimpanzees appear to comprehend others' goals and derive basic inferences, but there is no supporting evidence that they can consciously reflect upon their own mental states or even understand others' beliefs, abilities that in contrast are found in human infants [51,52]. We find no evidence for meta -representations of cultural knowledge in other primate groups have not been found.

Differences in meta-representational ability may thus account for the key differences between human and nonhuman cultures, more specifically relating to limitations in cumulative behavior and normative conformity as discussed above [21]. Tomasello [37] in a similar vein argues that meta-representation is a key adaptation enabling humans to understand other individuals as intentional agents like themselves and can engender cultural learning from a very young age. He argues that this ability emerges in young human infants around one year of age and enabling the acquisition of language and tool use practices. Finally, echoing the prominent role of metacognition in humans) [53] assert that the distinctively human cumulative cultural evolution is attributable to capacities for explicit metacognition.

An awareness of others' mental states, however, is necessary for successful teaching and the transmission of cultural information. Csibraand Gergely [54] argue for the universality of natural pedagogy among human groups. Despite the vast differences cross-culturally in child-upbringing practices, all human cultures directly depend on communication, both verbal and non-verbal, to transmit to novices diverse types of cultural knowledge including information about types of artefact, conventional behaviours, symbolisation, and cognitively opaque skills. Data pertaining to early hominin technological culture supports the postulation of natural pedagogy as an independently selected adaptive cognitive system, rather than arising as a by-product of another human-specific adaptation like language. In line with Csibra and Gergely, Heyes [55] states that human primates are born pupils. She argues that human infants genetically inherit a conglomeration of psychological adaptations that enhance their receptivity to teaching.

\section{Collaboration}

Tomasello and Hermann [56] argue that one major distinction between human and non-human primates involves their ability to function in cultural groups. The highest cognitive achievements in humans do not derive from individuals acting by themselves, but rather through individuals collaborating in groups. Great apes, particularly chimpanzees, coordinate their actions with other members of their groups in myriad ways - for example, they capture small animals and construct coalitions and alliances in intragroup conflicts [57]. Humans in contrast collaborate and communicate with each other in especially complex and elaborate ways. Their complex social institutions reflect joint goals, division of labour, and communicative symbols. In comparison to non-human apes who exploit others' perspectives for their own purposes, human infants make use of their perspective-taking skills to facilitate information sharing with others and for cooperative communication with them. Finally, some data suggest that chimpanzees and humans might differ in their underlying motivation to engage in a cooperative activity. There is some evidence that human infants demonstrate greater motivation to collaborate than chimpanzees. For example Reckers, Haun, and Tomasello [58] have found that human infants, but not chimpanzees, favour collaborative over individual food acquisition and these authors make a case for motivation being one key element underlying the evolution of human-like cooperation.

\section{Imagination}

Agustín Fuentes [59] argues that creativity and an ability to cooperate at an unprecedented scale were the major forces involved in human evolution. Deploying recent findings from evolution, biology, and archaeology, he proposes that human progress has been driven by creativity and cooperation. Furthermore, in his view the human capacity to move backwards and forwards between what is and what could be, and to share that information with others, is responsible for our lineage's success [59]. For him humans are a unique type of mammal, primate, and hominoid that observe the world, 
see it as it is, imagine novel possibilities, and reshape material reality. Fuentes [25] argues that much evidence exists that humans possess substantial ability to transform the shape of ecosystems, but this requires substantial efforts of collaboration and creativity.

But do other non-human primates possess imagination? According to Mithen [60] it remains clear that chimpanzees do not possess a creative imagination. This ability is found only in humans and sets them apart from theirs hominid ancestors. For this author creative imagination pertains to the capacity to unite different forms of knowledge and ways of thinking to develop creative and new ideas. This ability is not observed in chimpanzees and humans are uniquely creative. Unlike chimpanzees, humans have deployed their imagination to construct complex material and social networks.

\section{Conclusion}

Both humans and apes are members a group of primates known as the Hominoidea and as such both groups hold in common similar characteristics including complex social groups, large brains and the capacity to deploy tools. While humans and non-human primates, particularly chimpanzees, exhibit some similarities in terms of psychological ability, human culture is significantly more sophisticated than its non-human primate counterpart. In this respect primatologist Frans de Waal [61] points out that: 'Emotionally and socially, the psychology of chimps is very similar to humans'. For him the main difference is in the use of symbols and the use of language. Finally, Fuentes [25] argues that humans are distinctive and the complex social lives in humans exist because of the very fact that humans are primates. He proposes that humans are distinct in terms of their marked ability to significantly transform ecosystems: 'The human baseline of creative cooperation, the ability to think, communicate, and collaborate with increasing prowess, transformed us into beings who invented the technologies that support domestication, economies, large-scale societies, warfare, and broad-scale peace. This collaborative and imaginative capacity for creativity also drove the development of religious beliefs and ethical systems, and even the production of artwork. Such capacities fueled and facilitated our ability to compete in more deadly ways. Today humans deploy many of the same capacities that enabled our success as a species to kill/control other humans and manipulate the planet to the brink of ecological devastation'.

However, it is necessary to remain cautious in relation to evolutionary insights. The assumption is often made that chimpanzees and humans share similar evolutionary pathways, but this assertion has been criticized [25]. In order to draw evolutionary conclusions through the comparison of species, we must ensure that we are comparing the same underlying evolutionary processes and that "similar" patterns are indeed similar. It is significant, therefore, that most of chimpanzee and human behaviour today is not directly comparable on account of the fact that human and non-human primates have evolved independently for millions of years.

\section{References}

1. Chasiotis A (2011) Evolution and culture. Online Readings in Psychology and Culture.
2. Cole M, Meshcheryakov BG, Ponomariov IV (2011) Cross-cultural research in the cultural-historical activity theory tradition. In: FJR van de Vijver, A Chasiotis, SM Breugelmans, Fundamental questions in Cross-Cultural Psychology. Cambridge University Press, Cambridge, UK, 261-287.

3. Poortinga Y (2015) Is "Culture" a workable concept for (Cross-) cultural psychology?. Online Readings in Psychology and Culture 2.

4. Keller H(2002) Development as the interface between biology and culture: A conceptualization of early ontogenetic experiences. In: H Keller, YH Poortinga, A Scholmerich, Cambridge studies in cognitive perceptual development. Between culture and biology: Perspectives on ontogenetic development. Cambridge University Press, New York, USA, 215-240.

5. MacLean E (2016) Unravelling the evolution of uniquely human cognition. PNAS 113: 6348-6354.

6. Heyes $C$ (2012) New thinking: The evolution of human cognition. Philos Trans R SocLond B Biol Sci 367: 2091-2096.

7. Tomasello M, Call J (1997) Primate cognition. Oxford University Press, New York.

8. Laland KN, Galef BG (2009) The question of animal culture. Harvard University Press, Cambridge, USA.

9. Sahlins M (1976) The Use and abuse of biology: An anthropological critique of sociobiology. University of Michigan Press, Ann Arbor, USA.

10. Boesch E (2012) From material to symbolic cultures: Culture in primates. In: J Valsiner, The Oxford handbook of culture and psychology. Oxford University Press, Oxford, 677-694.

11. Fragaszy D, Perry S (2003) The Biology of Traditions: Models and Evidence. Cambridge University Press.

12. Boesch C (1996) The emergence of cultures among wild chimpanzees. In: WG Runciman, JM Smith, RIM Dunbar, Proceedings of The British Academy, Evolution of social behaviour patterns in primates and man. Oxford University Press, New York, USA, 251-268.

13. McGrew WC (1992) Tool-use by free-ranging chimpanzees: The extent of diversity. Journal of Zoology 228: 689-694.

14. KE Langergraber, C Boesch, E Inoue, et al. (2011) Genetic and 'cultural' similarity in wild chimpanzees. Proc Roy Soc B 278: 408-416.

15. Kawamura S (1959) The process of sub-culture propagation among Japanese macaques. Primates 2: 43-60.

16. Whiten A (2017) A comparative and evolutionary analysis of the cultural cognition of humans and other apes. Span J Psychol 19: E98.

17. Gruber T, Muller MN, Strimling P, et al. (2009) Wild chimpanzees rely on cultural knowledge to solve an experimental honey acquisition task. Curr Biol 19: 1806-1810.

18. Whiten A, Goodall J, McGrew WC, et al. (1999) Cultures in chimpanzees. Nature 399: 682-685.

19. JD Pruetz, P Bertolani, K Boyer Ontl, et al. (2015) New evidence on the tool-assisted hunting exhibited by chimpanzees (Pan troglodytes verus) in a savannah habitat at Fongoli, Senegal. Royal Society Open Science.

20. Mithen S (1996) The Prehistory of the mind. Thames and Hudson, London.

21. Gruber T, Zuberbuehler K, Clement F, et al. (2015) Apes have culture but may not know that they do. Frontiers in Psychology 6.

22. Hill K (2009) "Animal culture"?," in The Question of Animal 
Culture. In: Laland KN, Galef BG, Harvard University Press, Cambridge, USA, 269-287.

23. Perry S (2009) "Are nonhuman primates likely to exhibit cultural capacities like those of humans?,". In: Laland KN, Galef BG, The Question of Animal Culture. Harvard University Press, Cambridge, USA.

24. Whiten QA, Erdal D (201) The human socio-cognitive niche and its evolutionary origins. Philosophical Transactions of the Royal Society B 367: 2119-2129.

25. Fuentes $A$ (2018) How Humans and apes are different, and why it matters. Journal of Anthropological Research 74: 151.

26. Musgrave S, Morgan D, Lonsdorf E, et al. (2016) Tool transfers are a form of teaching among chimpanzees. Scientific Reports 6: 34783.

27. Tomasello M (1990) Cultural transmission in the tool use and communicatory signaling of chimpanzees? In: Parker ST, Gibson KR, 'Language' and intelligence in monkeys and apes: Comparative developmental perspective. Cambridge University Press, NY, USA, 274-311.

28. Galef BG (1992) The question of animal culture. Hum Nat 3: 157178.

29. Galef BG (2009) "Culture in animals?," in The Question of Animal Culture. In: Laland KN, Galef BG, Harvard University Press, Cambridge, USA, 222-246.

30. Zuberbuhler K, Gygax L, Harley N, et al. (1996) Stimulus enhancement and spread of a spontaneous tool use in a colony of long-tailed macaques. Primates 37: 1-12.

31. Whiten A, Mcguigan N, Marshall-Pescini S, et al. (2009) Emulation, imitation, over-imitation and the scope of culture for child and chimpanzee. Philos Trans R Soc B Biol Sci 364: 2417-2428.

32. Csibra G, Gergely $G$ (2006) Social learning and social cognition: The case for pedagogy. In: Munakata $Y$, Johnson $\mathrm{MH}$, Processes of change in brain and cognitive development. Attention and performance. Oxford University Press, Oxford, UK, 249-274.

33. Csibra G, Gergely G (2009) Natural pedagogy. Trends Cogn Sci 13: 148-153.

34. Thornton A, Raihani NJ (2010) Identifying teaching in wild animals. Learn Behav 38: 297-309.

35. Csibra G, Gergely G (2013) Teleological understanding of actions. In: Banaji MR, Gelman SA, Navigating the social world: What infants, children, and other species can teach us. Oxford University Press, 38-43.

36. Pradhan GR, Tennie C, Van Schaik CP (2012) Social organization and the evolution of cumulative technology in apes and hominins. J Hum Evol 63: 180-190.

37. Tomasello M (2001) Cultural transmission: A View from chimpanzees and human infants. Journal of Cross-Cultural Psychology 32: 135-146.

38. Tomasello M (1999) The cultural origins of human cognition. Harvard University Press.

39. Dean LG, Vale GL, Laland KN, et al. (2014) Human cumulative culture: A comparative perspective. Biol Rev Camb Philos Soc 89: 284-301.

40. Yamamoto S, Humle T, Tanaka M (2013) Basis for cumulative cultural evolution in chimpanzees: Social learning of a more efficient tool-use technique. PLOS ONE 8: e55768.

41. Whiten A (2005) The second inheritance system of chimpanzees and humans. Nature 437: 52-55.

42. Hopper LM, Schapiro SJ, Lambeth SP, et al. (2011) Chimpanzees' socially maintained food preferences indicate both conservatism and conformity. Anim Behav 81: 1195-1202.

43. Claidiere N, Whiten A (2012) Integrating the study of conformity and culture in humans and nonhuman animals. Psychol Bull 138: 126-145.

44. van de Waal E, Borgeaud C, Whiten A (2013) Potent social learning and conformity shape a wild Primate's foraging decisions. Science 340: 483-485.

45. Deutsch M, Gerard HB (1955) A study of normative and informational social influences upon individual judgment. J Abnorm Soc Psychol 51: 629-636.

46. van Schaik CP (2012) Animal culture: Chimpanzee conformity? Curr Biol 22: 402-404.

47. Whiten A, van de Waal E (2017) Social learning, culture and the 'socio-cultural brain' of human and non-human primates. Neurosci Biobehav Rev 82: 58-75.

48. Kaufmann L, ClEment F (2014) Wired for society: Cognizing pathways to society and culture. Topoi 33: 459-475.

49. Tomasello M, Carpenter M, Call J, et al. (2005) Understanding and sharing intentions: The origins of cultural cognition. Behav Brain Sci 28: 675-735.

50. Carruthers P (2002) The cognitive functions of language. Behavioral and Brain Sciences 25: 674.

51. Call J, Tomasello M (2008) Does the chimpanzee have a theory of mind? 30 years later. Trends Cogn Sci 12: 187-192.

52. Crockford C, Wittig R, Mundry R, et al. (2012) Wild chimpanzees inform ignorant group members of danger. Curr Biol 22: 142-146.

53. Dunstone J, Caldwell CA (2018) Cumulative culture and explicit metacognition: A review of theories, evidence and key predictions. Palgrave Communications 4.

54. Csibra G, Gergely G (2011) Natural pedagogy as evolutionary adaptation. Philos Trans R Soc B Biol Sci 366: 1149-1157.

55. Heyes C (2016) Born pupils? Natural pedagogy and cultural pedagogy. Perspect Psychol Sci 11: 280-295.

56. Tomasello M, Herrmann E (2010) Ape and human cognition: What's the difference? Current Directions in Psychological Science 19: 3-8.

57. Muller MN, Mitani JC (2005) Conflict and cooperation in wild chimpanzees. Advances in the Study of Behavior 35: 275-331.

58. Rekers $Y$, Haun D and Tomasello M (2011) Children, but not chimpanzees, prefer to collaborate. Current Biology.

59. Fuentes A (2017) The creative spark: How imagination made humans exceptional. Penguin.

60. Mithen S (2007) Seven steps in the evolution of the human imagination. In: Roth I, Imaginative Minds. Oxford University Press.

61. De Waal F (2009) Quoted in C Choi Human Evolution, our Closest Living Relatives.

DOI: $10.36959 / 763 / 500$

Copyright: (C) 2019 Dein S. This is an open-access article distributed under the terms of the Creative Commons Attribution License, which permits unrestricted use, distribution, and reproduction in any medium, provided the original author and source are credited. 